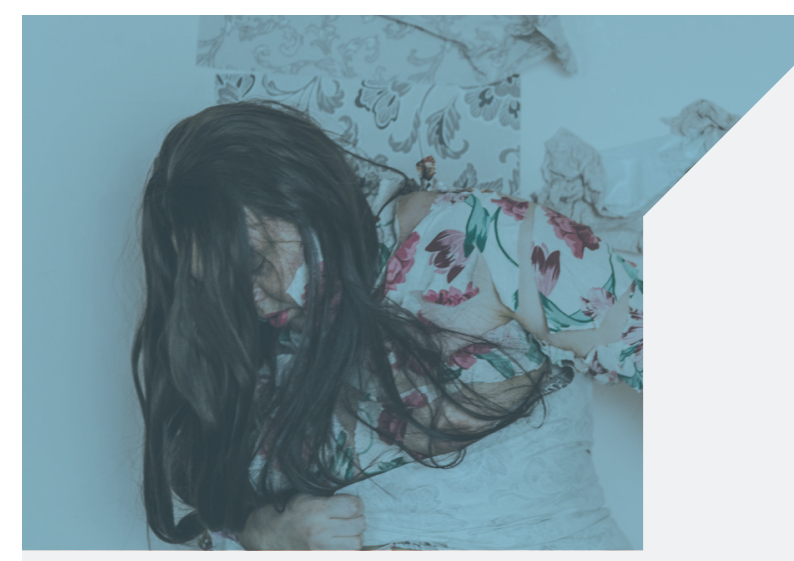

\title{
A MODULAÇÃO DA IDEIA DE "FORMAÇÃO DO BRASIL" NA CRÍTICA LITERÁRIA: CONTINUIDADES E DIVERGÊNCIAS ENTRE ANTONIO CANDIDO E ROBERTO SCHWARZ
}

THE MODULATION OF THE IDEA OF "FORMATION OF BRAZIL" IN LITERARY CRITICISM:

CONTINUITIES AND DIVERGENCES BETWEEN ANTONIO CANDIDO AND ROBERTO SCHWARZ Fernando Cambauva Breda

$$
\begin{aligned}
& \text { *cbreda59@gmail.com } \\
& \text { Mestrando do Programa de Pós-Graduação em Teoria e História } \\
& \text { Literária da Universidade Estadual de Campinas (Campinas - SP). O } \\
& \text { presente artigo é decorrente da pesquisa de mestrado em andamento } \\
& \text { com apoio da Fundação de Amparo à Pesquisa do Estado de São }
\end{aligned}
$$
Paulo (FAPESP), processo 2018/12355-1.

RESUMO: Categoria de grande importância na vida intelectual brasileira, a ideia de "formação do Brasil" guarda relação profunda com os projetos de modernização nacional que se foram estabelecendo no país, sobretudo, a partir da década de 1930. Tendo em vista que os diferentes projetos de modernização nacional possuem divergências significativas entre si, reduzi-los a um modelo único seria uma "abstração violenta" (SAYER, 1987). Por outro lado, ao assumirem certa tarefa histórica de "fazer o país", permitem-nos pensá-los em conjunto. Não é por acaso, portanto, que tal noção figure, em título ou "em espirito", em alguns dos textos mais importantes do pensamento social brasileiro. No caso da crítica literária, ela é central na modulacão do pensamento de ticas, procurarei neste trabalho disculir e histonizar a maneira pela qual estes críticos acabam por mobilizar um cabedal metodológico comum, associado ideia de "formação", mas apontam para horizontes históricos distintos e, assim, apresentam diferenças das mais significativas entre seus trabalhos. Dess forma, algo da visão consagrada de Schwarz como continuador do trabalho de Candido é posto em discussão.

PALAVRAS-CHAVE: Modernização; Formação do Brasil; Horizonte de expectativas; Antonio Candido; Roberto Schwarz.

ABSTRACT-Category of great importance in the Brazilian intellectual life, the dea of "formation of Brazil" is deeply related to the national modernization projects that were established in the country, especially since the 1930s. Given that these projects of national modernization have significant divergences, reducing them to a single model would be a "violent abstraction" (SAYER, 1987) On the other hand, by assuming a certain historical task of "making the country", they allow us to think about them together. It is no coincidence, therefore that such a notion appears, in title or "in spirit", in some of the most importan texts of Brazilian social thought. In the case of literary criticism, it is central in modulating the thinking of two of its most prestigious agents: Antonio Candido and critical evaluations, I will try to discuss and historicize the way in which these critics end up mobilizing a common methodological approach, associated with the idea of "formation", but reveal the most significant differences between their works by pointing to different historical horizons. Thus, something of the consecrated view of Schwarz as a continuator of Candido's work is put into discussion.

KEYWORDS: Modernization; Formation of Brazil; Horizon of expectations; Antonio Candido; Roberto Schwarz. 
1. Cf.: ARANTES, 1992; WAIZBORT, 2007; ALMEIDA, 2007.

2. “No terceiro ano da faculdade comecei a enxergar o rumo que as ciências sociais tomavam. Estava ficando claro que o bom sociólogo era alguém que faria pesquisa empírica de preferência quantitativa com metodologia norteamericana. Eu senti que não era minha vocação. Fui, então, chorar as mágoas com Antonio Candido, que tinha passado para as letras, e naquele momento, estava em Assis. [...] Então fui até lá perguntar a ele o que achava da minha crise, que, mal comparando, já tinha sido a dele. Ele me estimulou e depois me convidou a ser assistente dele, desde que eu fizesse um mestrado em teoria literária e literatura comparada no estrangeiro" (SCHWARZ, 1997, sem página).

\section{INTRODUÇÃO}

Pensar em comparações entre Antonio Candido e Roberto Schwarz talvez beire o lugar-comum. Para além de serem figuras centrais no meio intelectual brasileiro, partilham de um mesmo ca mpo acadêmico, sendo Schwarz, provavelmente, o discípulo de Candido que mais tenha radicalizado algumas das proposições sugeridas por seu mestre no âmbito da crítica literária. Frente a isso, não é casual que a reflexão a respeito de convergências e divergências entre os dois não seja uma novidade.

Nesse sentido, o que se tem observado é que, dentre os trabalhos que procuraram pensar a relação entre um e outro, existe, de modo geral, uma visão rela tiva mente consagrada de Schwarz como continuador dos trilhos abertos por Candido ${ }^{1}$ Não é de espantar: para além do tratamento sempre elogioso entre as partes, Schwarz por mais de uma vez taxou Candido como seu mestre e, explicitamente, colocou-se como seu seguidor. No mais, foi o próprio Candido quem o "acolheu" na crítica literária qua ndo o então jovem e insatisfeito estudante de Ciências Sociais procurava se desgarrar da disciplina e empirismo da sociologia. ${ }^{2}$

Dessa forma, talvez possamos compreender melhor as razões pelas quais o tratamento público-textual de um para com o outro tende a obscurecer, se não mesmo obliterar as diferenças existentes entre seus trabalhos. De modo que, conforme aponta Alfredo Melo (2014), as divergências entre os dois são, com efeito, silenciosas. ${ }^{3}$

Não obstante, concordo com Melo em que tais divergências estão centradas menos numa abordagem metodológica do que no aspecto mais propria mente político-progra mático de suas críticas. Assim, por meio da comparação de alguns de seus textos mais importantes, procura rei pensar a questão a partir da ideia de Brasil e de formação nacional em seus trabalhos.

\section{FIOS DE CONTINUIDADE}

Analisando diferentes períodos e facetas do que se convencionou chamar de pensamento social brasileiro, Paulo Arantes aponta como marca histórica da vida intelectua brasileira uma espécie de senso de dualidades que atravessa diferentes matrizes ideológicas, sendo a ntes de tudo "expressão de uma experiência coletiva” de uma nação periférica, cujo prestígio intelectual orbita em torno da produção ideológica do centro do capitalismo (ARANTES, 1992, p. 22).

No caso, seria próprio da experiência intelectual brasileira estar com os olhos voltados para a vida e cultura dos países do centro do capitalismo e, ao mesmo tempo, para a vida brasileira realmente existente - o que, claro, revelaria descompassos. Restaria, assim, uma sociedade em cuja vida
3. Como alerta Melo, Co textos de Schwe aparece como objeto da análise dialética. Em nenhum estudo seu, Schwarz examina as contradições descontinuidades dacobra de Candido da maneira sistemática e cuidadosa como investiga as fraturas ideológicas das obras de Cyro dos Anios, Augusto de Cyro dos Anjos, Augusto de (MELO, 2014, p. 409; grifo do autor). 
4. É bastante interessante o debate que Tamis Parro procura fazer a respeito dessa convivência. Apoiando-se em debates historiográficos mais recentes do que os mobilizados por Schwarz Parron matiza o caráter incompatível entre liberalismo e escravidão: "A leitura de Schwarz abalouse, porém, quando ruiu o modelo interpretativo da história que lhe dava suporte e incompatibilidade entre liberalismo e escravidão passou a ser entendida não como intrínseca à história, mas como resultado de uma reformulação do conceito de liberalismo no final do século XIX. Tornou-se, então, evidente a todos que o estudioso inserira no processo histórico brasileiro e no texto machadiano ideias anacrônicas, formuladas por pesquisadores do século $X X$. A questão não seria se o liberalismo estava fora do lugar, mas se sua noção de liberalismo não estava fora do tempo" (PARRON, 20102011, p. 206; grifos do autor) ideológica coexistiriam ordens de pressupostos distintos e, a princípio, antitéticas: um exemplo dos mais elucidativos nesse sentido seria o da convivência local entre as ideias do liberalismo europeu e a escravidão. ${ }^{4} \mathrm{Um}$ país, portanto umbilicalmente associado ao "mundo moderno" do centro do capitalismo, ao mesmo tempo que pautado por lógicas sociais distintas. Isto posto, não seria mero acaso, portanto, que a vida mental de um país periférico, como o Brasil, estivesse impregnada de dualismos.

Como críticos literários cujas preocupações centrais orbitam, grosso modo, em ver a internalização, na forma literária, de aspectos externos (históricos) - o que por $\mathrm{s}$ só já é um dado de congruência entre seus trabalhos -, fo incontornável a Candido e Schwarz o enfrentamento da configuração antitética que essa dupla ordem impunha à vida mental e social brasileira. Para tanto, a mbos procuraram fugir à ideia de dois Brasis coexistentes num único espaço, propondo a existência de movimentos dialéticos que "englobassem" e explicassem a unidade brasileira de contrários.

Ainda que analisando objetos diferentes, a semelhança estrutural a que chegam algumas de suas leituras mais importantes é notável. Exemplo: analisando as Memórias de um sargento de milícias, Candido reconhece ali um princípio formal cujo movimento é oscilante entre os polos da ordem e da desordem; já Schwarz vê na fórmula narrativa das Memórias póstumas de Brás Cubas certo princípio de volubilidade, que permite ao narrador transitar a seu capricho pela ordem e desordem burguesas. Nos dois casos, o princípio orga nizador ao qual forma e vida social estão submetidas é marcado por uma dualidade fluida e interpenetrada por ordens distintas e, a princípio, contraditórias.

Acontece que, se, como dito, a semelhança estrutural salta aos olhos, há uma diferença profunda na valoração dessa fluidez: se Candido vê na possibilidade desse movimento uma diferença brasileira que facilitaria "a nossa inserção num mundo eventualmente aberto” (CANDIDO, 2010a, p 46), Schwarz vê na mesma possibilidade a enorme margem de arbítrio (caprichoso e senhorial) da elite brasileira (SCHWARZ, 2014, p. 87).

Levando-se adiante novas comparações, nota-se que as semelhanças metodológicas não se restringem apenas às dialéticas formuladas: a própria noção de literatura brasileira, enquanto estrutura histórica, aparece de modo semelhante em seus trabalhos. Uma análise rápida do lugar de Machado de Assis nas obras dos críticos expõe com alguma clareza a existência efetiva de um programa de estudos comum nesse sentido. Se na Formação da Literatura Brasileira, Machado é o ponto de fuga ao qual está voltada a historicização de Candido do desejo romântico de uma elite nacional em ter sua própria literatura, em Schwarz o mesmo Machado converte-se em
8. Segundo Marques (2009, p. 12), "a Geração Mariel foi antes de tudo a tomada

9. Em 1963, Rosales foi convocado para o serviço militar obrigatório, de ond deu baixa depois de ser internado no hospital de Mazorra, em Havana, por problemas psiquiátricos. En 1965, na Tchecoslováquia, sofreu uma demorada crise nervosa. Depois, na União Soviética, foi internado num hospital psiquiátrico e teve diagnóstico de esquizofrenia. De volta a Cuba, entre 1966 e 1967, também recebeu tratamento psiquiátrico, embora os médicos cubanos acreditassem que ele sofresse simplesmente de "transtornos de personalidade".

10. El juego de la viola (1967) foi finalista do prêmio Casa de las Américas - que tinha como júri, entre outros, os escritores Julio Cortázar e Noé Jitrik -, mas na época não chegou a ser publicado. 
ponto de partida de seu trabalho de maior fôlego - no caso sua leitura seminal da obra machadiana, que resultou em dois livros: Ao vencedor, as batatas (1977) e Um mestre na periferia do capitalismo (2000). Bem ou mal, Schwarz acaba por dar continuidade à Formação no exato ponto em que Candido encerra seu livro.

No mais, os próprios princípios de leitura que Schwarz mobiliza em seu trabalho sobre Machado são como que desdobramentos analíticos de caminhos já sugeridos por Candido na Formação. Vejamos:

Veremos que esse mestre admirável [Machado de Assis] se embebeu meticulosamente da obra dos predecessores. A sua linha evolutiva mostra o escritor altamente consciente, que compreendeu o que havia de certo, de definitivo, na orientação de Macedo para a descrição dos costumes, no realismo sadio e colorido de Manuel Antonio, na vocação analítica de José de Alencar. Ele pressupõe a existência dos predecessores, e esta é uma das razões de sua grandeza. [...] A sua aparente singularidade se esclarece, para o historiador da literatura, na medida em que se desvendam as suas filiações e, para o crítico, qua ndo as liga ao talento peculiar com que fecundou a fórmula do romance romântico, acrescentando à apresentação realista das relações sociais urbanas uma profundidade analítica, inacessível à bonomia de Ma nuel Antonio, mas pressentida pelo Alencar de Senhora e Lucíola, no qual se entronca diretamente (CANDIDO, 2000, p. 104-105).

Ora, o percurso analítico feito por Schwarz em Ao vencedor as batatas, por si só, já aponta para a realização de um programa de estudos muito parecido ao sugerido no trecho citado de Candido. ${ }^{5}$ Parece-me que ao procurar ver na obra de Machado algumas soluções encontradas para a criação de um romance brasileiro - pautando para tanto justamente uma compa ração com os impasses forma is que Alencar não soube superar -, Schwarz aca ba por levar adia nte, com rigor crítico e metodológico, as justifica tivas valorativas de Candido quanto à "maestria” (CANDIDO, 2000, p. 104-105) de Machado. Isto é, Schwarz procurou ver como se fecundou em Machado uma fórmula à brasileira do romance romântico, ou ainda, ver de que maneira a obra madura de Machado se constitui como o momento decisivo da formação da literatura brasileira.

Se a filiação é explícita, o sinal, todavia, é trocado: se Candido vê na obra de Machado a maturação formativa de uma suposta consciência literária nacional, em Schwarz ela surge como espécie de sismógrafo das inviabilidades formativas brasileiras. ${ }^{6}$ Assim, os juízos dos críticos sobre romance machadiano são quase que opostos: enquanto Candido propõe que ele engendra ria uma suposta "dimensão
5. O percurso é sinalizado pelos títulos dos capítulos quais sejam: I As ideias fora do lugar: II. A importação do romance e suas

contradições em Alencar

III. O paternalismo Alenci

racionalização nos primeiros

romances de Machado de

Assis.

6. Não custa recordar 0 impacto do golpe civil-milita de 1964 na compreensão schwarziana de Machado. Conforme aponta Paulo Arantes, Schwarz, ao ver que o golpe representava justamente a velha

combinação esdrúxula que

repunha o arcaico para

figuração do moderno,

procurou "redescobrir o

primeiro capítulo dessa

constelaçao na armação

da narrativa machadiana

deixando-se levar pelo

fio condutor da sintaxe

binária do sistema cultural

brasileiro, sobre cuja gênese o desfecho de 64 lançara nova luz" (ARANTES, 1992,

p. 59-60). 
universalista" (CANDIDO, 2011, p. 15-32), Schwarz encontra ali justamente a "nota específica" da experiência histórica brasileira, reveladora do descompasso brasileiro com a norma burguesa e, ao mesmo tempo, da "elasticidade com que a civilização burguesa se acomoda à barbárie” (SCHWARZ, 2014, p. 87).

A rigor, o que está em questão nos casos comentados é, em última análise, uma reflexão sobre as transformações estruturais a que se submetem as importações europeias em solo brasileiro - seja m as ideias liberais em solo escravista, seja a importação do romance, seja a criação de uma literatura nacional num país recém-formado, sem uma ideia de nação consolidada e dotado de uma vida intelectual rarefeita, etc.

Nesse sentido, o lugar que Machado ocupa na obra dos críticos é significativo pela centralidade em seus trabalhos de maior fôlego, ao mesmo tempo em que se insere em uma abordagem mais a mpla cujo foco é pensar as singularidades da formação histórica do país, relacionando-as às potencialidades e resistências locais para a realização de uma sociedade "moderna" (leia-se ta mbém europeia) entre nós. Da1 a recorrência da questão da "viagem das ideias" nos trabalhos de Candido e Schwarz, ou ainda, da sondagem de dialéticas entre o "local e o cosmopolita"/ "centro e periferia" como organizadoras da vida intelectual brasileira. De modo que, tanto na apreensão da transformação das "ideias viajadas" quanto na dialética que resulta dessas "viagens", o que se tem no horizonte é justamente a compreensão do que nos (im) possibilita, do que nos afasta e/ou aproxima da efetivação do sonho de transposição de uma sociedade modelar europeia para os trópicos.

Eis aí o nó pelo qual tentaremos entender melhor como uma tal afinidade metodológica, que chega ao ponto de engendrar leituras estruturais extremamente parecidas, pode, no entanto, e, ao mesmo tempo, apontar para juízos tão díspares.

\section{A FORMAÇÃO COMO PRINCÍPIO METODOLÓGICO}

Se destaca mos anteriormente que uma recorrência da vida intelectual brasileira tem sido um senso de contrários - a partir do qual Candido e Schwarz formularam suas dialéticas da "ordem e desordem" e da "volubilidade" -, é verdade ta mbém que a força que dá lastro a essas reflexões é a ideia de formação do país. Colocada por Paulo Arantes como uma linha de força tomada quase como obsessão pela intelectualidade brasileira, o conceito de formação diz respeito a um "modo de indagar-se sobre a viabilidade da realização da sociedade moderna entre nós" (ARRUDA; VILLARINO, 2016, p. 3), pautada no "ideal europeu de civilização relativa mente integrada" (ARANTES, 1997, p. 12). 
7. Ainda que Arruda Villarino reconheçam que o tema "não tenha sido infenso aos intelectuais dos oitocentos" (ARRUDA VILLARINO, 2016, p. 3), é difícil comparar sua força e vitalidade entre os anos 1920 e 1960 com períodos anteriores ou posteriores. Uma chave de leitura que nos permite sondar certo sentimento de possibilidade foi proposta por Perry Anderson em seu texto "Modernidade e revolução" (ANDERSON, 1986).

Segundo ele, determinadas coordenadas históricas, em geral vistas em sociedades em vias de consolidação uma modernidade urban e capitalista, engendram vida coletiva um certo senso de proximidade histórica com alterações estruturais significativas. Nesse sentido, 1920 e 1960 brasileiros teria sido marcado por esse sentimento de possibilidade
Nesse sentido, Arruda e Villarino destaca que não é casual que os chamados clássicos da formação tenham surgido justamente no auge das disputas sobre o sentido da modernidade brasileira - período que vai, grosso modo dos anos 1920 a mais ou menos o início da década de 1960. ${ }^{7}$ Ainda segundo Arruda e Villarino, o paradigma da formação conformou-se de tal maneira no seio da experiência intelectual brasileira que se tornou como que um problema incontornável à própria reflexão sobre a matéria histórica brasileira, independentemente da (in)validade contemporânea do mesmo paradigma.

Dessa maneira, para além (ou aquém) de um paradigma analítico ou categoria histórica, a ideia de formação pode ser lida ta mbém como uma estrutura de sentimento (WILLIAMS, 1979, p. 34) que vigorou por importantes momentos do século $\mathrm{XX}$ brasileiro. Isto é, um operador social etéreo e difuso como um sentimento que, ao mesmo tempo,tem a força determinante de uma estrutura. Trocando em miúdos, tratava-se de uma categoria analítica, normativa e sentimental assentada numa vaga ideia de que um "dia o Brasil daria certo" (ARANTES, 2016, p. 138)

Nesse sentido, um dos momentos chaves de elaboração formal do paradigma da formação no imaginário intelectual brasileiro parte justamente de Antonio Candido, quando da publicação de seu clássico livro Formação da literatura brasileira em 1959. Mesmo sendo considerada uma espécie de obra tardia dentro do paradigma, esta guarda importância significativa porque acabou por transformar a ideia de formação num princípio metodológico. A partir da noção de sistema literário, Candido criou uma espécie de fórmula metodológica que permite pensar de maneira sistemática a força cumulativa dos processos de consolidação de sistemas institucionais modernos em meio a uma suposta rarefação cultural brasileira. $^{8}$

Sua noção de sistema literário passava a operar como um mecanismo de averiguação e sondagem quanto à implementação de determinados padrões desejados pelos ideais formativos - a literatura nacional (aos moldes franceses), por exemplo. É como se Candido tivesse criado um método que se combinava à gramática de interpretação do Brasi forjada pelo paradigma da formação: um método, portanto, que procura dar conta do problema de sondagem da matéria histórica brasileira a partir do desvio em relação aos padrões europeu. Ou ainda, convertia em método o enfrentamento ao travejamento sociológico dos conceitos e instituições europeias na vida brasileira.

Isso posto, cabe retomarmos similitudes e afinidades metodológicas já abordadas entre Candido e Schwarz. Como bem recordam Leandro Villarino e Maria Arminda Arruda, ao converter-se em princípio metodológico, uma
8. Não por acaso, o mesmo método foi mobilizado para pensar a conformacão de outros sistemas culturais no Brasil (Filosofia, Teatro, Cinema, etc). Cf.: ARANTES, 1994: PRADO, 2001: SALLES GOMES, 1986. Sua presença foi tão impactante que o método chegou mesmo a ser pensado para outros países (cf. MACEDO, 2014). 
9. Não custa destacar também que essa mesma tradição epistemológic brasileira foi uma base comum de leituras históricas sobre o Brasil presentes na formação intelectual dos dois críticos em questão. Dentre as obras destacamse Formação do Brasil contemporâneo de Caio Prado Jr., Casa-grande \& senzala de Gilberto Freyre e Raízes do Brasil de Sergio Buarque de Holanda. das linhas de força central que "o tratamento da formação permitiria enfrentar [é] o deslocamento das ideias" (ARRUDA; VILLARINO, 2016, p. 4). Ora, volta mos aí justamente ao fio de continuidade que parece atar os trabalhos de Candido Schwarz. Minha hipótese é a de que a tão falada continuidade crítica entre Candido e Schwarz é de ordem metodológica e reside em um fazer crítico em que a análise literária articulase à "formação como princípio metodológico" (ARANTES, 1997, p. 20). Isto é, numa atividade crítica em que a análise imanente da forma literária está sempre articulada à sondagem da formação histórica da nação, pensada em contraposição à sociedade europeia tomada como modelo. Não por acaso, seus objetos de crítica são, no mínimo, dois: a forma e a nação como formação histórica; ou ainda a formação da forma e a formação da nação.

A partir disso, espero estar mais compreensível como tais críticos puderam chegar a leituras estruturais tão semelhantes... ${ }^{9}$ Resta agora sondarmos as razões de juízos político-estéticos tão díspares sobre questões comuns.

\section{SCHWARZ E CANDIDO DENTRO DO ARCO HISTÓRICO DA FORMAÇÃO}

Em depoimento de 2004, proferido em um eventohomenagem a Schwarz, Antonio Candido - a quem também ficou a tarefa de abrir o encontro - destacou que a sensação de dualidade era como que uma situação incontornável ao intelectual latino-americano, obrigado a "ser ele e mais um outro. Esse outro era a quota de cultura europeia da qua necessitava para se formar" (CANDIDO apud CEVASCO; OHATA, 2007, p. 15).$^{10} \mathrm{Em}$ momento mais adiante de sua fala, destacou que frente a essa dualidade, as reações são particulares:

Cada um de nós vive a seu a modo a dualidade a que estou me referindo. Em Roberto, acho que a experiência orgânica de dois polos nacionais, linguísticos e culturais ajudou a incliná-lo para os temas e as ideias de oposição e contraste, quem sabe até favorecendo o pendor para o lado do marxismo, cheio de sentimento dos antagonismos que estimula m e fundamentam o pensamento dialético. [...] Esse gosto pela tensão e contraste leva-o a privilegiar as obras e os autores problemáticos, que além disso permitam apreender as modalidades de correlação com a vida social (CANDIDO apud CEVASCO; OHATA, 2007, p. 16-17).

Ao que parece, Candido reconhece que no trabalho de Schwarz existe uma opção própria frente à dualidade. Ainda que se trate de um apontamento simples, há algo bastante significativo nessa distinção que Candido procura localizar entre ele próprio e seu pupilo. É como se houvesse uma
10. Verdade que Candido hoje as coisas estão muito diferentes devido à globalização, prefiro ficar na esfera do mundo em que me formei" (CANDIDO apud CEVASCO: OHATA, 2007, $15)$. 
localização histórica "escondida" na percepção de Candido quanto ao modo schwarziano de lidar com os dualismos; diferença, vale dizer, com importantes consequências progra máticas do próprio sentido da formação que é impresso em seus respectivos trabalhos.

Minha hipótese é a de que o entroncamento da ideia de formação na crítica de ambos é, em termos históricos, políticos e programáticos, radicalmente diferente, a despeito de suas similitudes metodológicas. A razão para tanto estaria no momento histórico em que cada um dos críticos entroncase nesta tradição: Candido, em um período ascensional de uma ideia progressista de formação nacional; e Schwarz, num momento de derrota geracional do vetor progressista dessa mesma tradição. Assim, ainda que a mbos adotem a categoria da formação como princípio metodológico, os sentidos que imprimem a ela são histórica e valorativa mente distintos.

Digamos, a fim de simplificar a questão, que dentro da própria ideia de formação atuem duas frentes que tanto podem se complementar positivamente, como podem se complementar à negativa. De um lado, temos um cabedal metodológico e analítico voltado à reflexão e interpretação da conjuntura brasileira. Ou seja, uma abordagem histórica sobre o "Brasil", a "cultura brasileira" e a "formação nacional" que procura sempre contrapô-los à experiência histórica europeia, tratada em boa medida como modelar. E que, como já dito, é convertida em "princípio metodológico" por Candido a partir da formulação de "sistema literário". De outro, existe uma disposição político-programática que tem como horizonte a modernização à europeia, no caso dos críticos, dos trópicos. Conforme lembrou Paulo Arantes (2017) ao discutir a "atualidade do pensamento de Roberto Schwarz", seria parte dessa "tradição formativa", portanto, uma certa epistemologia e/ou concepção histórica que pressupunha uma dimensão civilizadora do capitalismo, que um dia poderia vir a nos tocar. Nesse sentido, eram necessárias intervenções preparatórias à realização futura do país, ou ainda, ao seu ingresso no Primeiro Mundo. Trocando em miúdos, era necessário "dotar o meio gelatinoso com ossatura moderna" (ARANTES, 1992, p. 12) - o que não deixa de ser um aspecto normativo dessa tradição. É a partir da consideração desta segunda dimensão, bem como do enquadramento feito pelos críticos das possibilidades de realização deste projeto que podemos compreender melhor o sentido da divergência silenciosa de que estamos falando. Localizarmos o trabalho crítico de Candido e Schwarz dentro de um arco histórico da própria "tradição da formação" ajuda a sondar possibilidades de como podem ter chegado por métodos tão similares a resultados tão dessemelhantes.

Assim, ao situarmos o trabalho e pensamento de Candido como modulados por uma experiência ou uma estrutura de 
11. Ainda que compartilhe de vários apontamentos de Alfredo Melo, discordo de sua hipótese de que a divergência entre os críticos estaria assentada otimista e confiante no povo" e em um Schwarz "esquerdista frankfurtiano certo da inviabilidade do Brasil, em razão da desfaçatez de suas elites" (MELO, 2014, p. 413). O problema parece ser historicamente mais localizado e diz respeito à própria ideia de superação (ou a possibilidade dela) das iniquidades da vida social brasileira a partir de certa epistemologia histórica, no caso, a do paradigma da formação

12. Vale dizer que assumir uma dimensão nacionaledificante na prática de Antonio Candido e dos modernistas paulistas não significa aderir à visão de mundo expressa em suas obras. Pelo contrario: parto do pressuposto de que toda e qualquer atuação nacional-edificante tem sentimento calcadas num horizonte ascensional da ideia de formação, parece que muito de sua atuação como crítico ganha novos contornos. Da mesma maneira, se olharmos para obra de Schwarz como também modulada pela experiência histórica dessa tradição, marcada, no entanto, por uma derrota pessoal e de geração, parece-me que muito da divergência entre a mbos vem à tona.

Isso posto, poderíamos dizer, didaticamente, que a formação nacional estava posta no horizonte histórico que modula o trabalho de Candido; ao passo que na obra de Schwarz é a própria inviabilidade de uma formação naciona integradora que marcará decisivamente sua produção intelectual de maior fôlego. ${ }^{11}$ Ainda que em a mbos os casos, haja a incorporação de seu aspecto metodológico.

\section{A POSITIVIDADE FORMATIVA DE CANDIDO}

Pessoalmente ligado ao modernismo paulista, Antonio Candido compartilhou com eles não só experiências pessoais como ta mbém certo espírito de geração nacional-edificante ${ }^{12}$. Dessa maneira, tal como se deu especialmente com Mário de Andrade, foi central a muito dos trabalhos de Candido uma preocupação significa tiva em forjar uma nova ideia de Brasil calcada, sobretudo, em pesquisas sobre cultura popular e na institucionalização de sistemas culturais - no seu caso, o da crítica literária. Não por acaso, duas linhas de força também fundamentais à tradição formativa de que viemos falando.

No entanto, diferentemente dos modernistas, Candido avaliava que a tarefa edificante que cabia à sua geração era quase que a verificação crítica e metodologicamente rigorosa do que teria sido aberto pela geração de 1920. Conforme depoimento de Candido:

Me parece fora de dúvida que a minha geração é uma geração crítica. O que leva a admitir que, se é assim, é porque passamos no Brasil, ou pelo menos em São Paulo, por uma fase que exige um esforço de aclaramento, de compreensão, de classificação. [...] É claro que toda geração encontra problemas a solucionar e deixa outros tantos. Os da geração famosa de 20, que aqui em São Paulo se coloca quase imedia tamente antes da nossa, formaram também, a seu modo uma geração crítica. [...] De qualquer modo, porém, abriram caminho para o estudo de muitos problemas brasileiros e colocaram a necessidade do trabalho que hoje fazemos. Sob este aspecto, somos os seus continuadores (CANDIDO apud DANTAS, 2002, p 240-243).

Nesse sentido, ainda que com variações ao longo do tempo, já desde o princípio de seu trabalho estava delineada uma espécie de progra ma crítico que o a nimará em grande medida historicamente operado com construções, e também, destruições, exclusões e silenciamentos na criação de seus próprios mitos de identidade nacional. 
13. Faço referência aqui à coluna "Notas de crítica" publicada nos jornais Folha de S. Paulo (de janeiro de 1943 a janeiro de 1945) e Diário de S. Paulo (de setembro de 1945 a fevereiro de 1947) ao longo de sua carreira. Além disso, cabe acrescentar que, mais do que um "reparo a ser feito" nos problemas deixados pela geração que lhe antecedera, há toda uma modulação da experiência e de responsabilidades históricas na atuação de Candido que guarda relação direta com a estrutura de sentimento da formação da qual falamos anteriormente. Era necessário fazer o Brasil. Como se, para Candido, a superação da rarefação intelectual brasileira compreendesse ta mbém a existência e/ou criação de uma crítica qualificada.

Isso posto, é necessário dizer que, naquilo que se propôs, sua trajetória foi extremamente efetiva - independentemente, aos nossos propósitos, do valor crítico e/ou historiográfico de seus trabalhos. Nela, procuraremos acompanhar muito resumidamente três aspectos/momentos dos mais significativos: seus esforços na consolidação da Teoria Literária como disciplina universitária, a publicação da Formação da literatura brasileira em 1959 e a organização do Instituto de Estudos da Linguagem da Unicamp.

Seguindo algumas das proposições de Rodrigo Ramassote (2011), é possível verificar já no período inicial da atuação de Candido como crítico literário ${ }^{13}$ uma preocupação fundamental em diferenciar-se do que chamava de uma crítica impressionista, feita em geral por bacharéis. $\mathrm{Na}$ concepção de Candido, o que estava em jogo era menos a especialização (ou a ausência delas, no caso) de seus "colegas de profissão" do que propriamente a perspectiva de análise a que submetiam suas críticas. Para o crítico, muitos deles praticavam uma a nálise literária demasiadamente subjetiva, deixando de lado aspectos que para ele eram fundamentais à a nálise literária: "o que há de mais fundamente cultural, isto é, o que nelas significa o caráter comum de todas as obras de uma cultura" (CANDIDO apud RAMASSOTE, 2011, p 41).

Se nesse primeiro momento, as polêmicas no âmbito da crítica literária em que esteve envolvido restringiamse a querelas jornalísticas, a situação muda de tom significativamente a partir 1959, ano de publicação de Formação da literatura brasileira, e dos primeiros movimentos para a introdução da Teoria Literária como disciplina do curso de Letras da Universidade de São Paulo.

Podemos dizer que o ano de 1959 figura como um momento de virada no que diz respeito a seus projetos de formação institucional de uma crítica literária brasileira. A disciplina formulada em 1959 é implementada em 1961, consolidando-se na própria USP nos anos seguintes. No mais, foi tornada modelo institucional, sendo como que exportada à Universidade Estadual de Campinas em 1977, ${ }^{14}$ como também passou a organizar, ainda que indiretamente, variados cursos de Letras em âmbito nacional. Além disso, o reconhecimento nacional e internacional de Formação da literatura brasileira foi tão significativo que não seria exagero
13. Conforme Ramassote: "A julgar pelas rubricas dos cursos oferecidos, o modelo

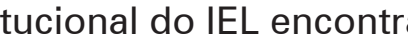
convergências estreitas om o padrão de atividades studos estabelecido no curso de TLLC [Teoria 
15. Em texto discutindo uma abordagem sobre a literatura brasileira a ser feita em curso de graduação a ser ministrado em Portugal, Abel Barros Baptista propõe que “o caráter luso-brasileiro do conhecido fosso que separa as duas literaturas - ou seja, o fato de ser cavado pela exclusão recíproca - fica muito bem ilustrado pelo nome de Antonio Candido. Por um lado, é impossível a um sujeito aproximar-se da literatura brasileira sem que de imediato depare com ele, desde logo, na influente teoria da literatura brasileira teoria da literatura brasileira, da literatura brasileira (1959)" (BAPTISTA, 2005, p. 41). taxá-lo como a mais influente proposição historiográfica sobre a literatura nacional, pautando de modo bastante incisivo o que viria a ser o cânone literário brasileiro. ${ }^{15}$

Ora, se estiver claro até aqui - a partir das providências institucionais do crítico - que há sim uma dimensão positiva no horizonte formativo de Candido, é necessário também avaliar como isto se dá na própria a tividade crítica do autor Talvez um caminho para sondarmos o entroncamento da positividade formativa de Candido em seu trabalho crítico seja revendo algumas posições em um de seus trabalhos mais importantes: o ensaio "A dialética da malandragem", publicado em 1970.

A escolha se dá por ser um de seus textos ma is reconhecidos e por ilustrar aspectos de sua divergência com Schwarz. De modo que, no escopo do que estamos nos propondo a pensar, é um ensaio elucidativo das distintas posturas dos críticos diante das possibilidades de formação do Brasil.

Neste ensaio, Candido propõe, a partir da análise do romance Memórias de um sargento milícias, que o livro estaria orga nizado sob o princípio formal da dialética da ordem e da desordem, ou da dialética da malandragem. Isto é, um romance cujo mundo figurado em suas páginas seria regido por uma lógica de vida ideologicamente identificada com as classes dominadas brasileira; ou melhor, com uma delas, no caso, os homens livres pobres do Brasil oitocentista. Seguindo o raciocínio do crítico, tratava-se de uma novidade na novelística brasileira por seu popularismo inédito, o que lhe tornava mais próximo das formas espontâneas da vida social Ainda segundo Candido, o romance engendraria, assim, uma articulação mais funda com a vida social brasileira a partir de um realismo bastante singular, em que a vinculação mimética com o Real estaria internalizada na obra menos como tema do que como princípio organiza tivo de expressão.

Independentemente da acuidade analítica (ou não) da leitura de Candido, interessa-nos pensar na interpretação crítica que ele confere ao romance. Há na visão do crítico uma espécie de entusiasmo incontido com esse mundo figurado nas Memórias Vejamos: frente a "toda a sorte de acomodações (ou negações), que por vezes nos fazem parecer inferiores ante uma visão estupidamente nutrida de valores puritanos, como a das sociedades capitalistas", o Brasil poderia dar sua contribuição civilizacional a partir de uma cultura "regida por encantadora neutralidade moral" em que as dualidades se operam por acomodação e/ou aplainamento de quinas (CANDIDO, 2010a p. 46). ${ }^{16}$ Como se vê, trata-se de um verdadeiro elogio ao "mundo sem culpa", supostamente figurado no livro.

Dessa forma, para voltarmos à comparação que nos guia, é interessante pensar que nos "choques entre a norma e a
16. A proximidade da ideia de aplainamento das quinas com a concepção de Gilberto Freyre de uma dimensão na cultura brasileira que punha os antagonismos em equilíbrio vale uma reflexão mais aprofundada. 
conduta", no quais Schwarz viu "a elasticidade com que a civilização burguesa se acomoda à barbárie", Candido vê "formas espontâneas da sociabilidade" atuantes no sentido de abrir alternativas mais flexíveis de futuro - como se a formação do Brasil, desde que pautada numa espécie de moralidade popular-culturalista própria, pudesse ser um legado civilizatório e moderno do país à humanidade. Como se vê, procurando ela borar uma síntese aos dualismos no seio mesmo de um ensaio, Candido incorpora um sentido positivo à formação nacional brasileira. Ou ainda, nas palavras de Wisnik, introduz em seu ensaio um culturalismo convertido em "elogio das peculiaridades brasileiras natas" (WISNIK, 2008, p. 424).

\section{A INFLEXÃO NEGATIVA DE SCHWARZ}

Um dos meios possíveis para se sondar a negatividade forma tiva do pensa mento de Roberto Schwarzé a comparação de sua produção inicial, especialmente os textos de $A$ sereia e o desconfiado (1965) e alguns d'O pai de família e outros estudos (1978), com os trabalhos produzidos a partir da década de 1970, sobretudo de Ao vencedor as batatas (1977) em diante. Ao vê-los em movimento, percebem-se duas inflexões bastante significativas de sua proximidade distante com Candido: a incorporação da formação como princípio metodológico e a assunção da inviabilidade formativa brasileira como horizonte crítico.

Em seu primeiro livro de críticas publicado, o que de imediato salta aos olhos é a marca forte e central, para não dizer solitária em alguns casos, das análises formais. Nelas, Schwarz procura esmiuçar os princípios construtivos das obras a nalisadas, pautando, em sua valoração, a construção (ou não) do mundo como realidade mutável. Dito de outra maneira, existe uma espécie de reivindicação generalizada da incorporação formal de um tempo histórico progressivo, muito próprio da noção de Realismo do autor que exercia sobre Schwarz maior influência naquele momento: György Lukács.

Assim, nestes textos de juventude, mesmo quando o objeto de análise são obras literárias brasileiras, não existe propriamente uma preocupação específica com a matéria histórica brasileira, preocupação que marcará seus escritos posteriores. Pensando naquilo que nos interessa: nesses escritos a incorporação da formação como princípio metodológico ainda não se havia realizado. ${ }^{17}$

Tal processo de incorporação, no entanto, já se mostra visível em alguns dos artigos publicados em $O$ pai de família. Neles, ainda que a reivindicação de certo "realismo como método" esteja presente, sua preocupação com o agencia mento
17. Segue declaração do proprio Schwarz a respeito: "Penso que a diferença estaria em que, no primeiro livro, meu esforço era o de apreender a coerência ou incoerência formal dentro de um espectro ideológico muito genérico, digamos, da luta entre ideias de direita e de esquerda, ou da tensão entre as contradições da ordem burguesa e

um horizonte socialista; enquanto que, mais tarde, comecei a procurar a ligação entre esse tipo de problema e as suas bases históricas, no plano da estrutura social. [...] De certo modo, em $A$ Sereia e o Desconfiado, eu ficava na metade do meu programa, que já era o de agora. Hoje penso que faco uma parte maior" (SCHWARZ, 1979, sem página). 
histórico já não está mais posta em abstrato (ou em termos universalizantes): é a realidade brasileira que anima a questão, sempre com vistas à sua integração formativa. O fio de continuidade metodológica que ataria seu trabalho ao de Candido passava ao centro de suas reflexões. Um exemplo expressivo (e salvo engano, pioneiro) dessa inflexão é a crítica que faz em 1964 ao romance O amanuense Belmiro de Cyro do Anjos: ali, para além da análise formal, já se vislumbra uma tentativa de formalização de um certo tempo histórico brasileiro, cheio de combinações acomodatícias, que parecia não se adequar ao tempo histórico progressivo (do realismo lukasciano) prezado em seus escritos de juventude. Assim, ainda que não seja propriamente o tema central do ensaio, a reflexão crítica sobre a especificidade histórica do Brasil já despontava tangencialmente na pena do crítico.

Será, contudo, somente a partir da publicação em 1977 de Ao vencedor as batatas que, finalmente, a reflexão sobre a experiência histórica passaria definitivamente ao centro de suas reflexões - aproximando-o de vez da gramática formativa compartilhada com Antonio Candido.

Assim, se no texto sobre o romance de Cyro do Anjos é possível vislumbrar os primeiros movimentos daquilo que o aproxima de Candido - a saber, a incorporação da matéria histórica brasileira como constitutiva da análise literária e, no mais, pensada em comparação com a experiência histórica europeia -, é também importante ter em mente que ta operação se realiza no contexto logo posterior ao golpe civilmilitar de 1964. Para além de frear possíveis novos contornos ao andamento histórico brasileiro, o tempo histórico que se abria com a ditadura vai dar novo sentido - negativo - ao horizonte formativo do pensamento de Schwarz. Assim, justo no momento em que a matéria histórica brasileira passava ao centro de suas reflexões, suas possibilidades de formação se fechavam em simultâneo, aos olhos do crítico, por conta do golpe civil-militar.

De modo bastante ilustrativo, essa nova configuração histórico-epistemológica (que incorpora o aspecto metodológico da formação no mesmo momento em que assume sua inviabilidade política) parece se cristalizar em seu ensaio “Cultura e política: 1964-1969", tal como foi publicado em O pai de família, isto é, com a nota preliminar que lhe põe reparos e foi inserida na edição de 1978 . Vejamos:

As páginas que seguem foram escritas entre 1969 e 1970 No principal, como o leitor facilmente notará, o seu prognóstico estava errado, o que não as recomenda. Do resto, acredito - até segunda ordem - que alguma coisa se aproveita. A tentação de reescrever as passagens que a realidade e os anos desmentiram naturalmente existe. 
Mas para que substituir os equívocos daquela época pelas opiniões de hoje, que podem não estar menos equivocadas? Elas por elas, o equívoco dos contemporâneos é sempre mais vivo. Sobretudo porque a análise social no caso tinha menos intenção de ciência que de reter e explicar uma experiência feita, entre pessoal e de geração, do momento histórico. Era antes a tentativa de assumir literariamente, na medida de minhas forças, a atualidade de então. Assim, quando se diz 'agora', são observações, erros e alternativas daqueles anos que têm a palavra. O leitor verá que o tempo passou e não passou (SCHWARZ, 1978, p. 61).

Mesmo compartilhando do aparato metodológico de seu mestre Açu-Acê - corruptela de Antonio Candido, a quem, não por acaso, O pai de família é dedicado - já aí se vislumbra, pelos reparos feitos anos depois, que um diferente, novo e rebaixado leque de expectativas se punha no horizonte histórico de Schwarz. Era o a fasta mento do pupilo em relação ao mestre, a opção própria frente aos dualismos.

Diante da grande densidade do ensaio, cabe pinçar do texto justamente aquilo que convém aos nossos propósitos: a referida inflexão e rebaixamento do horizonte formativo de Schwarz. Para tanto, parece haver dois momentos significativos: sua análise sobre o tropicalismo e a própria nota preliminar.
Em meio à sua aguda análise das razões do golpe civilmilitar de 1964, bem como da situação cultural do país nos a nos subsequentes, Schwarz dedica não pouca atenção aos tropicalistas, ou melhor, à fórmula artística que criaram. Grosso modo, segundo ele, os tropicalistas formularam uma imagem do país em que o conteúdo arcaico era tra tado em forma "avançada", fecundando uma fórmula alegórica nacional de justaposição indiferenciada entre antigo e novo em que "na composição insolúvel mas funcional dos dois termos, portanto, está figurado um destino nacional, que dura desde os inícios" (SCHWARZ, 1978, p. 91)... Novamente esta mos diante de certa reivindicação do Realismo, agora já não mais posta em termos abstratos, mas profundamente calcados na realidade local: ao longo do texto, Schwarz critica de modo ferino uma suposta sugestão de destino nacional veiculada nas imagens tropicalistas, defendendo que tal sugestão era problemática por essencializar problemas históricos, mesmo que esteticamente bem realizada.

Ocorre que menos de dez anos depois, quando da publicação do ensaio em livro, Schwarz decide acrescentar ao texto a nota preliminar transcrita acima. Nela, além de assumir que seu prognóstico estava errado (opção pela luta armada?), tangencialmente sugere que a virada entre a nota e o texto é fruto da revisão de uma "experiência feita, entre pessoal e de geração". A se avaliar pela sua produção posterior à nota 
preliminar, parece que ali houve uma importante mudança no horizonte histórico de expecta tivas do crítico que lhe dará novos sentidos à ideia de formação nacional, bem distintas da que encontra mos no próprio ensaio, por exemplo.

Salvo engano, tal rebaixamento do horizonte histórico vai se radicalizando - a percepção de que o capitalismo vai "empilhando vitórias" (SCHWARZ, 2014, p. 162) passa a ser mais profundamente assumida na crítica de Schwarz -, dando novos contornos, sobretudo, à noção de Realismo. Nesse sentido, sua revisão crítica sobre a Tropicália é especialmente interessante, bem como a própria noção de Realismo que advoga à literatura de Machado. No que diz respeito à Tropicália, a diferença é gritante: se no final da década de 1960, ela era vista como alegoria ambígua sobre a modernização conservadora de 1964, em 2011 a avaliação é bastante distinta (e menos reivindicativa, por assim dizer):

sem prejuízo das convicções políticas contrárias do autor [Caetano Veloso], o absurdo tropicalista formaliza e encapsula a experiência histórica da esquerda derrotada em 1964, e sua verdade (SCHWARZ, 2012, p. 101).

Ainda sobre isso, é oportuno ter em mente que tal acepção de Realismo está diretamente ligada às suas pesquisas sobre Machado. Nelas, Schwarz propõe que a objetivação da realidade em Machado acaba por dar novos contornos ao Realismo, conferindo-lhe uma especificidade brasileira, ou ainda, periférica: justamente a de um tempo histórico não progressivo em que as coisas mudam justamente para continuarem iguais. A despeito das derrotas históricas, o ganho crítico é relevante.

\section{À GUISA DE CONCLUSÃO}

Um último ponto a se notar a respeito da "divergência formativa” entre Candido e Schwarz guarda relação com o aspecto ideológico a que ambos estão submetidos.

Se é verdade que Candido, ao procurar nas classes populares saídas aos impasses dualistas brasileiros, acabou por transformar, como notou o próprio Schwarz, "um modo de ser de classe em modo de ser nacional", o mesmo raciocínio valeria para o próprio Schwarz? Se o culturalismo de Candido é um problema porque sua positividade formativa perderia de vista uma visada crítica (da maior importância) aos movimentos do capital, o programa crítico e radicalmente negativo de Schwarz não poderia realizar uma aproximação perigosa com uma visão (elitizada?) de mundo que encontra bastante dificuldade em ver movimentos nas lutas de classes para além daqueles realizados pelos que mandam - e a 
consequente desagregação social que estes movimentos vêm gerando?

Sem procurar dar alguma resposta nesse sentido, caberia lembrar uma autocrítica do próprio Schwarz em depoimento sobre o Seminário Marx:

ao aprofundar a análise de classe, o seminário especificava a imensa e desconcertante liberdade dos movimentos da riqueza em face dos oprimidos do país [...]. Com efeito, a constatação da margem de liberdade absurda e antissocial de que a classe dominante dispõe no país, foi um dos resultados a que a contragosto chegavam nossos estudos marxistas. (SCHWARZ, 2014, p. 102)

Não há dúvida de que a crítica radical ao capital é parte imprescindível de um programa de estudos que se proponha a rechaçar o status quo; por outro lado, a pesquisa de potências das lutas e formas de resistências populares é, considero, parte fundamental de um programa crítico contemporâneo.

\section{REFERENCIAS}

ALMEIDA, Jorge de. "Pressupostos, salvo engano, dos pressupostos salvo engano". In: CEVASCO, Maria Elisa; OHATA, Milton. Um crítico na periferia do capitalismo: reflexões sobre a obra de Roberto Schwarz. São Paulo: Companhia das Letras, 2007, p. 44-53.

ANDERSON, Perry. Modernidade e revolução. Novos Estudos CEBRAP. São Paulo, v. 14, p. 2-15, fev. 1986.

ARANTES, Paulo. Sentimento da Dialética. Rio de Janeiro: Paz e Terra, 1992.

. Um Departamento Francês de Ultramar. Rio de Janeiro: Paz e Terra, 1994.

Providências de um crítico literário. In: ARANTES, Paulo ARANTES, Otília. Sentidos da formação. Rio de Janeiro: Paz e Terra 1997, p. 7-66.

. Da noite para o dia. In: Coletivo DAR. (Org.). Dichavando o Poder: drogas e autonomia. $1^{\mathrm{a} e d . S a ̃ o ~ P a u l o: ~ A u t o n o m i a ~ l i t e r a ́ r i a, ~}$ 2016, p. 137-165.

A atualidade do pensamento de Roberto Schwarz. In A ATUALIDADE DE ROBERTO SCHWARZ, 2017, Guarulhos, UNIFESP. Disponível em: < https://www.youtube.com/ watch? $\mathrm{v}=0 \mathrm{JJEw1Nc1sd0}>$. Acesso em: 02 mar. 2020.

ARRUDA, Maria Arminda do Nascimento; VILLARINO, Leandro Vizin. 0 conceito de formação em tempos críticos: esboço de reflexão. Anais $40^{\circ}$ Encontro Anual da ANPOCS. São Paulo: ANPOCS, 2016. 
BAPTISTA, Abel de Barros. 0 livro agreste. Campinas: Editora da Unicamp, 2005

CANDIDO, Antonio. Na sala de aula: caderno de análise literária. São Paulo: Editora Ática, 1998.

Iniciação à literatura brasileira. São Paulo: Humanitas/ FFLCH-USP, 1999

Formação da literatura brasileira: momentos decisivos. Belo Horizonte: Editora Itatiaia, 2000.

. "Sobre Roberto Schwarz" CEVASCO, Maria Elisa; OHATA, Milton. Um crítico na periferia do capitalismo: reflexões sobre a obra de Roberto Schwarz. São Paulo: Companhia das Letras, 2007, p. 13-17. $2010 \mathrm{a}$.

O discurso e a cidade. Rio de Janeiro: Ouro sobre azul $2010 \mathrm{~b}$.

Literatura e sociedade. Rio de Janeiro: Ouro sobre azul,

. Vários escritos. Rio de Janeiro: Ouro sobre azul, 2011.

DANTAS, Vinicius. Bibliografia de Antonio Candido / Textos de intervenção. São Paulo: Duas cidades/Editora 34, 2002.

MACEDO, Tania Celestino. A presença da literatura brasileira na formação dos sistemas literários dos países africanos de língua portuguesa. In: ABDALA JR., Benjamin. (Org.). Estudos comparados: Teoria, Crítica e Metodologia. Cotia: Ateliê Editorial, 2014, v. 1, p. 443-478.

MELO, Alfredo Cesar. Pressupostos, salvo engano, de uma divergência silenciosa: Antonio Candido, Roberto Schwarz e a modernidade brasileira. Alea [online]. 2014, vol.16, n.2, p. 403-420.

PARRON, Tamis. Disputas de poder no ocaso do império: uma leitura de 0 Alienista. Revista USP, n. 88, p. 199-206, 2011.

PRADO, Décio de Almeida. 0 Teatro Brasileiro Moderno. São Paulo: Perspectiva, 2001.

RAMASSOTE, Rodrigo M. A formação dos desconfiados: Antonio Candido e a crítica acadêmica (1961-1978). 2006. Dissertação (Mestrado em Antropologia Social) - Instituto de Filosofia e Ciências Humanas da Unicamp, Campinas, 2006.

. Inquietudes da crítica literária militante de Antonio Candido. Tempo Social, revista de sociologia da USP, v. 23, n. 2, p. 41-70, 2011.

SALLES GOMES, Paulo Emílio. Cinema: trajetória no subdesenvolvimento. Paz e Terra, 1986.

SAYER, Derek. The Violence of Abstraction. Oxford: Basil Blackwell, 1987. 
SCHWARZ, Roberto. 0 pai de família e outros estudos. Rio de Janeiro/ São Paulo: Paz e terra, 1978.

“Entrevista com Gildo Marçal Brandão e 0. C. Louzada Filho". Encontros com a Civilização Brasileira, Rio de Janeiro, n.15, 1979. Disponível em: < https://arlindenor.com/2012/08/29/698/ > Acesso em: 16 jul. 2018

A sereia e o desconfiado. Rio de Janeiro: Paz e terra

"Entrevista". Entrevista concedida a Fernando de Barros Silva. Folha de S.Paulo, 01/06/97. Disponível em: < https://www1. folha.uol.com.br/fsp/mais/fs010608.htm >. Acesso em: 16 jul. 2018

Que horas são? São Paulo: Companhia das Letras, 2006

Ao vencedor as batatas. São Paulo: Duas cidades/Editora $34,2012 a$

Um mestre na periferia do capitalismo - Machado de Assis. São Paulo: Duas cidades/Editora 34, 2012b.

Martinha versus Lucrécia. São Paulo: Companhia das Letras, 2012c.

Sequências brasileiras: ensaios. São Paulo, Companhia das Letras, 2014.
WAIZBORT, Leopoldo. "Ouem herda não furta", In: CEVASCO, Maria Elisa; OHATA, Milton. Um crítico na periferia do capitalismo: reflexões sobre a obra de Roberto Schwarz. São Paulo: Companhia das Letras, 2007, p. 33-43.

WILLIAMS, Raymond. Marxismo e literatura. Rio de Janeiro: Zahar, 1979.

WISNIK, José Miguel. Veneno remédio - o futebol e o Brasil. São Paulo: Companhia das Letras, 2008

Recebido em: 15-08-2019. Aceito em: 12-03-2020. 